\title{
The seismicity, fault structures, and stress field in the seismic gap adjacent to the 2004 Mid-Niigata earthquake inferred from seismological observations
}

\author{
Kazutoshi Imanishi ${ }^{1}$, Yasuto Kuwahara ${ }^{1}$, Tetsuya Takeda ${ }^{1 *}$, and Yoshikatsu Haryu ${ }^{2}$ \\ ${ }^{1}$ Geological Survey of Japan, AIST, AIST Tsukuba Central 7, 1-1-1, Higashi, Tsukuba, Ibaraki 305-8567, Japan \\ ${ }^{2}$ National Research Institute for Earth Science and Disaster Prevention, 3-1, Tennodai, Tsukuba, Ibaraki 305-0006, Japan
}

(Received July 22, 2005; Revised January 27, 2006; Accepted February 17, 2006; Online published July 26, 2006)

\begin{abstract}
We investigate the seismicity, fault structures, and stress field in the southern seismic gap adjacent to the source region of the 2004 Mid-Niigata earthquake based on precise earthquake locations and focal mechanism solutions. The double-difference earthquake locations reveal detailed fault structures including five discrete clusters. A stress tensor inversion method indicates that, at the southern ends of the Muikamachi and the Tokamachi faults, the stress state changes from thrust faulting to a strike-slip faulting regime. We show two possibilities for the deepfault geometry of the southern part of the Muikamachi fault. Our preferred fault geometries of the Muikamachi fault differ from that of the mainshock, especially for the geometry of the dip direction. It is likely that the Muikamachi fault is divided into two segments whose boundary corresponds to the southern end of the source region of the 2004 event, and that the rupture area was terminated due to this fault segment boundary. The Coulomb failure stresses that are induced by the mainshock and the largest aftershock increase at the southern part of the Muikamachi faults. Furthermore, the angle between the maximum principal stress and the preferred fault planes implies that the shear stress resolving along the planes are large. This evidence suggests a high seismic risk in the seismic gap.
\end{abstract}

Key words: The 2004 Mid-Niigata earthquake, seismicity, fault structure, stress field, seismic gap, temporary seismic observation, microearthquake.

\section{Introduction}

The October 23, 2004, $\mathrm{M}_{\mathrm{JMA}}=6.8$ Mid-Niigata earthquake occurred in an active folded region in central Japan. The focal mechanism of this earthquake was a reverse faulting whose strike was about $\mathrm{N} 35^{\circ} \mathrm{E}$, which is typical in the area. The mainshock was followed by a large number of aftershocks, including one, the largest, of $\mathrm{M}_{\mathrm{JMA}}=6.5$. The aftershock distributions show complex fault structures in the source region including sub-parallel fault planes (the mainshock and the largest aftershock) and conjugate fault planes (Aoki et al., 2005; Sakai et al., 2005; Shibutani et al., 2005). Double-difference tomography reveals that the hanging wall side of the mainshock has lower seismic velocities and the footwall side has higher ones (Kato et al., 2005; Korenaga et al., 2005; Okada et al., 2005; Takeda et al., 2005).

When a large earthquake occurs, the seismic risk in adjacent regions increases because of large stress concentrations due to the size of the earthquake. In fact, there is much observational evidence that adjacent regions are successively ruptured. The 2004 Sumatra-Andaman Island and the 2005 Northern Sumatra earthquakes are typical examples. The migration of earthquakes is also known to occur, with the

*Present address: National Research Institute for Earth Science and Disaster Prevention, 3-1, Tennodai, Tsukuba, Ibaraki 305-0006, Japan.

Copyright (C) The Society of Geomagnetism and Earth, Planetary and Space Sciences (SGEPSS); The Seismological Society of Japan; The Volcanological Society of Japan; The Geodetic Society of Japan; The Japanese Society for Planetary Sciences; TERRAPUB most frequently cited case being a sequence of earthquakes along the North Anatolian fault. It should be noted that such triggering of earthquakes in adjacent regions is not limited to the plate boundary faults. For example, the 1982-1985 Coalinga sequence occurred beneath the northern half of a 110-km-long fold chain bounding the eastern California Coast Ranges (Stein and Ekström, 1992). These successive failures have been well explained by the Coulomb stress transfer (Stein et al., 1997; Lin and Stein, 2004). Since the calculation of the Coulomb stress transfer depends on assumptions of fault geometry and faulting type, it is necessary to investigate the fault structures and stress states in adjacent regions before an earthquake occurs in order to improve our ability to forecast earthquake hazards.

The 1828 Sanjou earthquake (M6.9) and the 1847 Zenkouji earthquake (M7.4) occurred on the north and south sides of the source region, respectively (Fig. 1). Although the source areas of both of these earthquakes are poorly understood because of historical events, it is likely that the 1847 Zenkouji earthquake occurred at the western marginal fault zone of the Nagano basin and that there exists a seismic gap between the 2004 Mid-Niigata earthquake and the 1847 Zenkouji earthquake. Note that there are two active faults within the seismic gap, namely the Muikamachi and Tokamachi faults (Fig. 1).

The purpose of this study is to investigate the seismicity, fault structures, and stress state in the seismic gap adjacent to the source region of the 2004 earthquake based on seismological analyses. We analyzed earthquakes that 


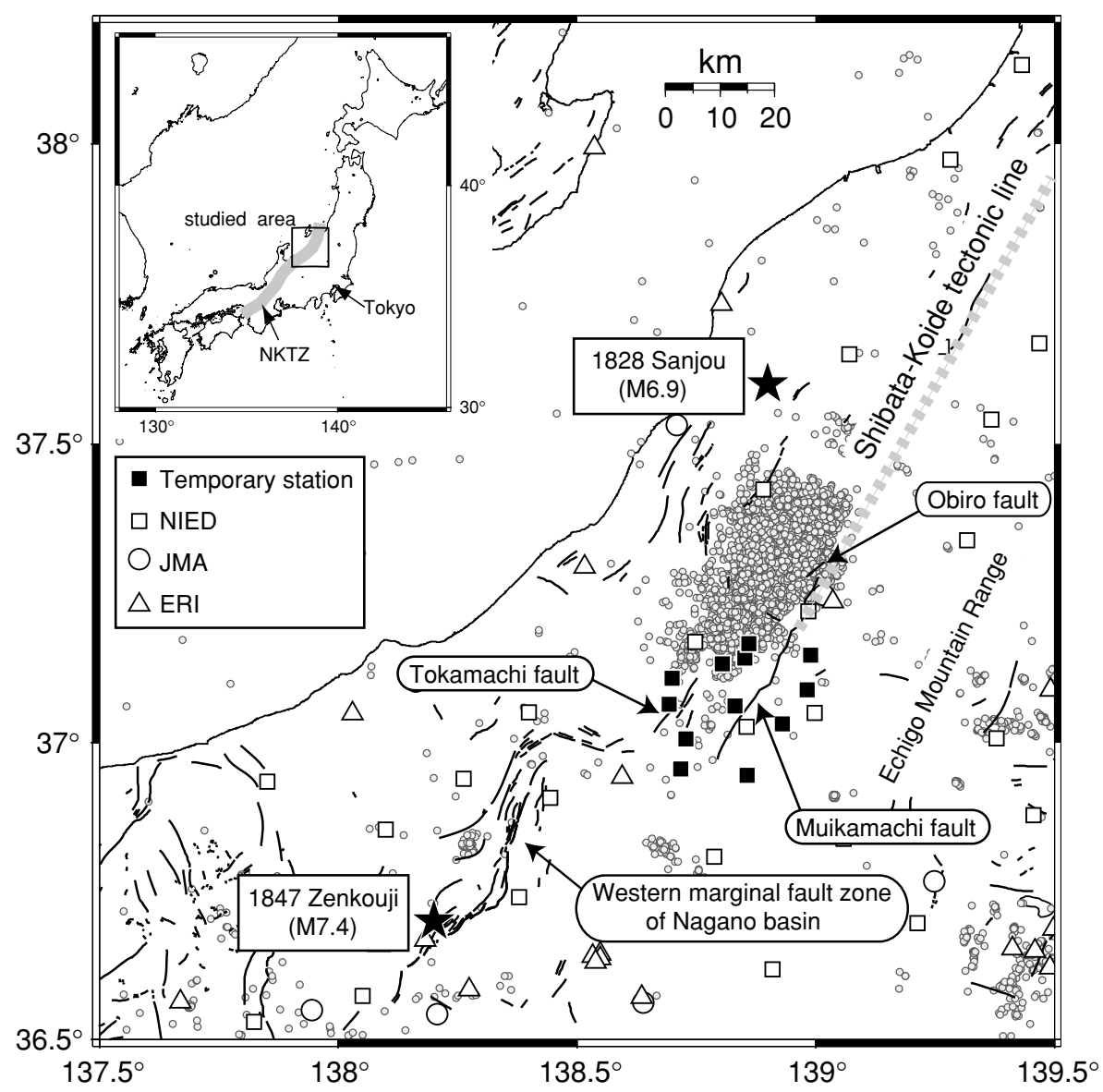

Fig. 1. Map of the Niigata region, central Japan. Gray circles mark the epicenters of aftershocks determined by JMA for the period from October 23 to December 31 . Temporary stations are represented by closed squares. Permanent stations operated by NIED (open squares), JMA (circles) and ERI (triangles) are also shown. Solid lines represent active faults (Research Group for Active Faults in Japan, 1991). Closed stars are the epicenters of the 1828 Sanjou earthquake (M6.9) and the 1847 Zenkouji earthquake (M7.4) according to Utsu (1999). The broken line is the Shibata-Koide line. The thick gray line in the inset shows the concentrated deformation zone (NKTZ).

occurred in the seismic gap during the period from June 3, 2002 to April 30, 2005. Since the permanent stations around the seismic gap are not always sufficient for this type of analysis, we performed a dense temporary seismic observation with a spacing of $5-10 \mathrm{~km}$ beginning in November 25,2004 . We added waveform data obtained from the beginning of this temporary observation until December 24, 2004. Although the temporary observation data might be insufficient at present, it is necessary to produce the best results that we can as soon as possible because of the high seismic risk in the seismic gap. It should be noted that even if the temporary data are not sufficient, they are useful for correcting earthquake locations during the period before and after the temporary observations.

\section{Geological and Tectonic Setting}

The source region and the present studied area are covered with thick sediments of Neogene and Quaternary, while the eastern side, Echigo Mountain Range, is mainly composed of pre-Tertiary and igneous rocks of Early Miocene (e.g., Yanagisawa et al., 1985, 1986). The boundary between the source region and the Echigo Mountain Range corresponds to the Shibata-Koide tectonic line (Fig. 1), which was formed as a normal fault under the opening of the Japan Sea during 20-15 Ma (e.g., Sato,
1994).

Hashimoto (1990) detected a high strain rates zone from Niigata to the Kinki district on the basis of analyses of triangulation data compiled over the past 100 years. The high strain rates zone was clearly identified in the recent observation of dense GPS arrays done by the Geographical Survey Institute (Fig. 1) and named the Niigata-Kobe Tectonic Zone (NKTZ) (Sagiya et al., 2000). The strain rate in the NKTZ exceeds $10^{-7} /$ year, which is 10 times higher than the average in Japan. Within this zone, there are many active faults, and a number of historically large earthquakes have occurred there. The 2004 Mid-Niigata earthquake occurred just inside the tectonic zone.

As mentioned above, there are two active faults in the seismic gap between the source region of the 2004 earthquake and the 1847 Zenkouji earthquake, the Muikamachi fault and the Tokamachi fault. The Muikamachi fault is a reverse fault with a length of about $30 \mathrm{~km}$ dipping to the northwest. The vertical slip rate of the fault is estimated to be $0.8-2.0 \mathrm{~mm} / \mathrm{yr}$ (e.g., Kim, 2001, 2004), which falls into the category of the highest slip rates in Japan. It should be noted that the southern part of the Muikamachi fault has not yet ruptured due to the 2004 earthquake (Fig. 1). The Tokamachi fault zone consists of western and eastern faults. The western Tokamachi fault is a reverse fault with a length of 


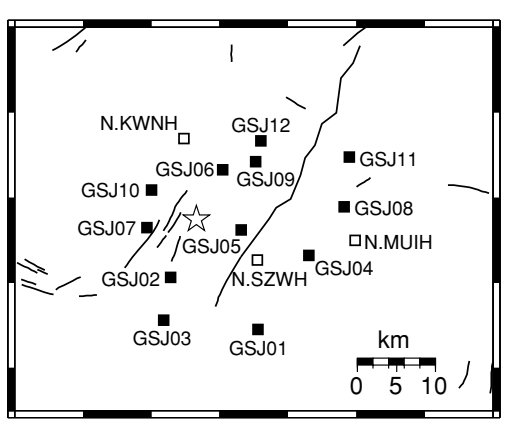

2004/12/09 20:55 (JST)

MJMA 1.4

Depth $=11 \mathrm{~km}$
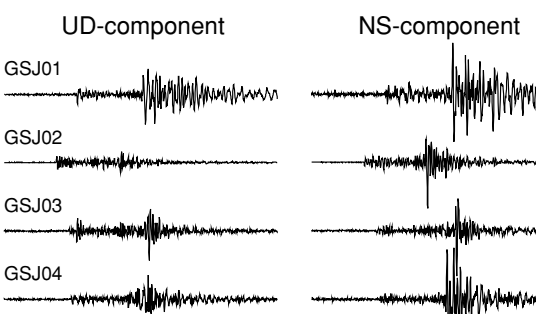

- Temporary station

$\checkmark$ NIED (borehole station)

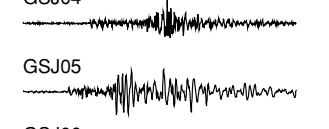

GSJ06
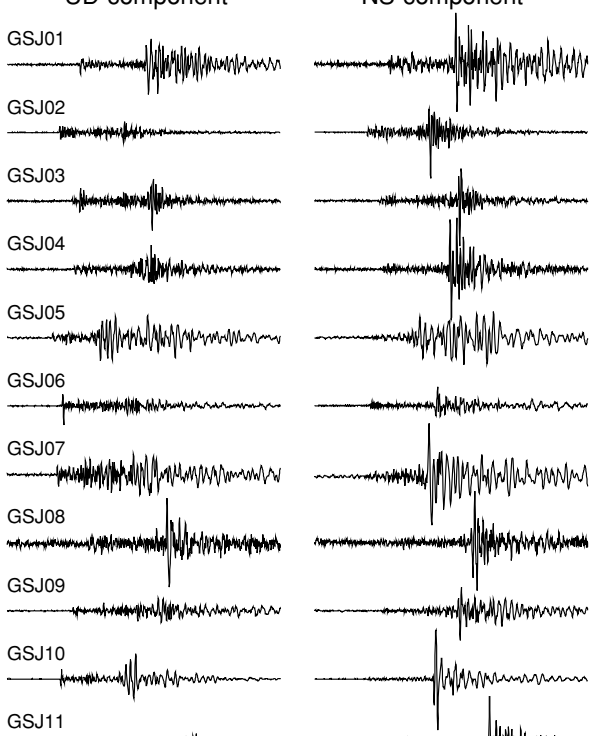

EW-component
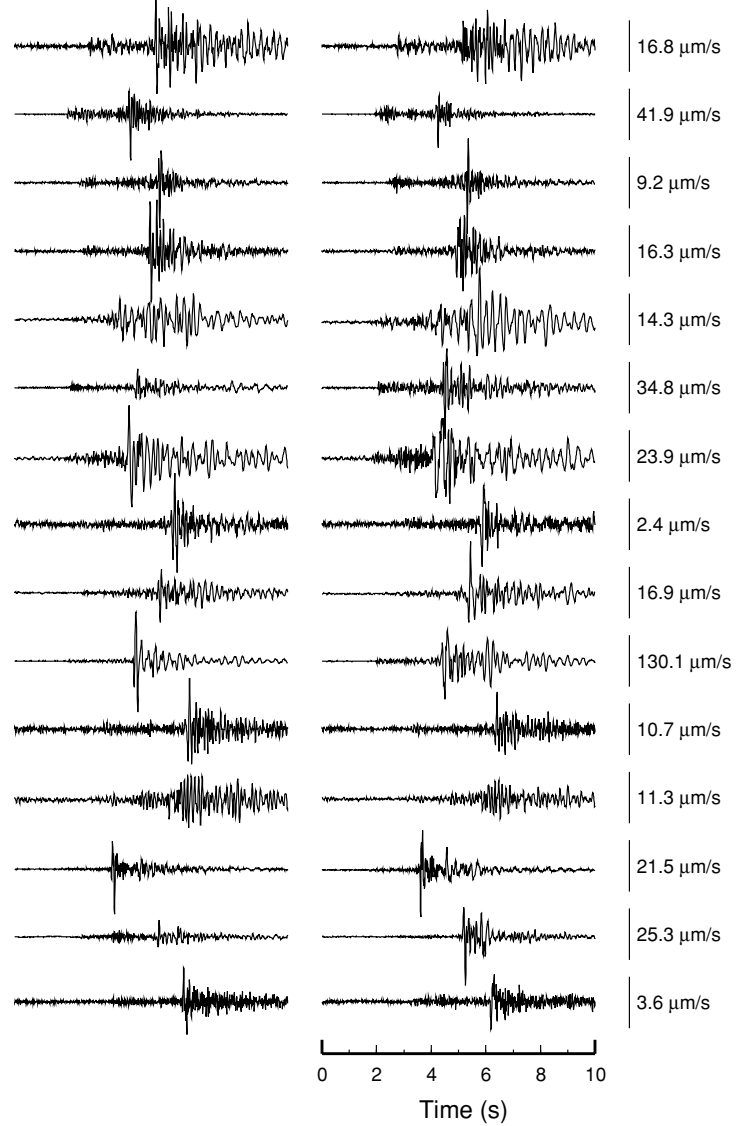

$16.9 \mu \mathrm{m} / \mathrm{s}$

$130.1 \mu \mathrm{m} / \mathrm{s}$

$10.7 \mu \mathrm{m} / \mathrm{s}$

$11.3 \mu \mathrm{m} / \mathrm{s}$

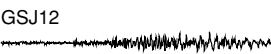

N.SZWH

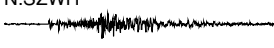

N.KWNH

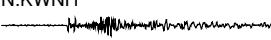

N.MUIH

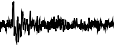

Fig. 2. An example of waveforms recorded by temporal stations and surrounding three borehole stations.

about $33 \mathrm{~km}$ dipping to the northwest (Ikeda et al., 2002). The vertical slip rate of the fault is estimated to be $1 \mathrm{~mm} / \mathrm{yr}$ (Neotectonics Research Group of the Niigata Shinano River Region, 2002). The eastern Tokamachi fault is also a reverse fault, but it dips to the southeast. The fault length is estimated to be about $19 \mathrm{~km}$. The vertical slip rate of the fault is estimated to be $0.2-1.4 \mathrm{~mm} / \mathrm{yr}$ (Tanaka, 2000). Thus, the Tokamachi fault also has the potential to cause significant damage in the surrounding area.

\section{Data}

Figure 1 shows the distribution of permanent stations in and around the present studied area operated by NIED (National Research Institute for Earth Science and Disaster Prevention), JMA (Japan Meteorological Agency) and ERI (Earthquake Research Institute, University of Tokyo). Each station is equipped with a set of three-component velocity transducers having a natural frequency of 1 or $2 \mathrm{~Hz}$. In particular, seismometers deployed by NIED are installed at the bottom of a borehole at a depth of several hundred meters (Okada et al., 2004).

We have made temporary observations using a dense seismic network from November 25, 2004, to the beginning of the following year. In micro-earthquake observations, seismometers should be installed at hard rock sites to record the high frequency components of waveforms and reduce the site-specific response. As mentioned above, the presently studied area is covered with thick sediments of Neogene and Quaternary. However, this area is well known as the landslide zone (Yanagisawa et al., 1985, 1986), and there exist many landslide prevention dams that are generally fixed on hard bedrock. Therefore, we installed most of the seismometers on top of the dams. We deployed 12 temporary stations spaced about 5 to $10 \mathrm{~km}$ from each other in a $20 \times 20 \mathrm{~km}$ area (Fig. 1). The seismometers used in the observations are three-component velocity transducers 


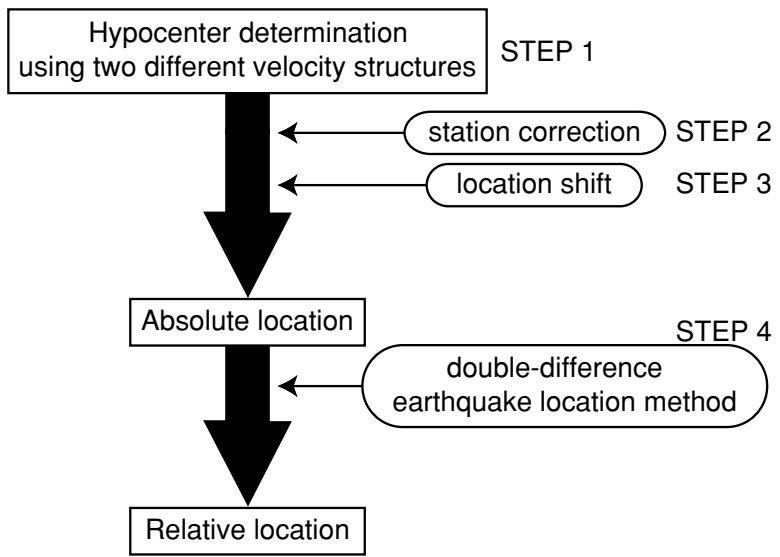

Fig. 3. Procedure for hypocenter determination.

having a natural frequency of $2 \mathrm{~Hz}$ (L22-E, Mark Products Inc.). Earthquakes were recorded on LS7000 data loggers (DATAMARK Inc.) with GPS clocks at sample rates of 100 $\mathrm{Hz}$ in off-line continuous mode. We retrieved data on December 23-24, 2004 and confirmed that the data quality was good. Figure 2 shows an example of waveforms recorded by the temporal stations and surrounding borehole stations. Except for those recorded at several stations (e.g., GSJ01, GSJ05, GSJ07), the seismograms contain high-frequency components of up to several tens of $\mathrm{Hz}$ and have small coda wave amplitudes. Distinct converted/reflected phases can be observed in the seismograms at many stations, suggesting heterogeneous structures in the present studied area.

Based on the JMA hypocenter catalogue, we selected 128 earthquakes that occurred at the southern end of the source region during the period from June 3, 2002 to April 30, 2005. We also included another 13 events that were newly detected by setting up temporary stations in our data set.

\section{Seismicity in the Seismic Gap}

A relation between the surface traces of active faults and earthquake locations is important in this study, so that precise absolute locations are required. In addition, we need relative locations of micro-earthquakes to reveal fine-fault structures. Figure 3 shows the procedure for the hypocenter determination. As described later, since the strong lateral variation of velocity exists in the studied area, we use two different velocity structures for the calculation of travel times. Most of the earthquakes analyzed in the present study occurred before the temporary station data were available. Since the average distance between the permanent stations is approximately $20 \mathrm{~km}$ (Fig. 1), the permanent stations alone are not always sufficient to precisely locate events shallower than $20 \mathrm{~km}$. To obtain absolute locations of these events as precisely as possible, we estimate the difference between the locations determined by both the permanent and temporary stations and those by only the permanent stations. The difference in hypocenters is considered in absolute locations. For the determination of relative earthquake locations, we apply the double-difference earthquake location algorithm of Waldhauser and Ellsworth (2000), which has been shown to produce sharp images of fault structure (Prejean et al., 2002).
Table 1. Velocity structure.

\begin{tabular}{|c|c|c|c|}
\hline \multicolumn{2}{|c|}{ Northwestern side } & \multicolumn{2}{|c|}{ Southeastern side } \\
\hline $\begin{array}{l}\text { Depth } \\
(\mathrm{km})\end{array}$ & $\begin{array}{c}P \text {-wave velocity } \\
(\mathrm{km} / \mathrm{s})\end{array}$ & $\begin{array}{l}\text { Depth } \\
(\mathrm{km})\end{array}$ & $\begin{array}{c}P \text {-wave velocity } \\
(\mathrm{km} / \mathrm{s})\end{array}$ \\
\hline $0-1$ & 2.5 & $0-2$ & 4.5 \\
\hline $1-5$ & $3-4.5$ & $2-18$ & 6.0 \\
\hline $5-18$ & 6.0 & $18-33$ & 6.7 \\
\hline $18-33$ & 6.7 & $33-$ & 8.0 \\
\hline $33-$ & 8.0 & & \\
\hline
\end{tabular}

\subsection{Absolute locations}

A refraction profile (Takeda et al., 2004), geology (Yanagisawa et al., 1985), and the Bouguer gravity anomaly (Geological Survey of Japan, AIST, 2004) suggest that there is a strong structural boundary around the ShibataKoide line. Therefore we assumed two different onedimensional crustal velocity structures on the northwestern and southeastern sides to determine the hypocenters of micro-earthquakes. The boundary between these structures coincides with the Shibata-Koide line and an earthquake fault of the 1847 Zenkouji earthquake (Fig. 1). The $P$-wave velocity model used in the present study is shown in Table 1, where the northwestern side has a lower velocity than the southeastern side at depths of less than $5 \mathrm{~km}$. The $S$-wave models are assumed by scaling the $P$-wave velocities by a factor $1 / \sqrt{3}$. The $P$ - and $S$-wave arrival times were identified manually using the WIN system developed by Urabe and Tsukada (1991). Using these two different velocity models and arrival times, the hypocenters were determined by a maximum-likelihood estimation algorithm (Hirata and Matsu'ura, 1987).

We first determined all of the earthquake locations without the arrival times at the temporary stations (step 1 in Fig. 3). We next relocated the hypocenters by introducing the station correction, which was obtained using the average of the residuals at each station (step 2 in Fig. 3). The rootmean-squares of the residuals decreased from 0.15 to $0.07 \mathrm{~s}$ for the $P$-wave and 0.26 to 0.16 s for the $S$-wave. The spatial errors are within $500 \mathrm{~m}$ in the horizontal direction and $1 \mathrm{~km}$ in depth.

We then compared the locations determined using the arrival times at both the permanent and temporary stations with those determined using only the permanent stations. During the period of the temporary observation, 20 events occurred in the seismic gap. Here we selected 16 events that have five or more $P$-wave arrival times at the permanent stations. Since these events are distributed at various locations and depths (black circles in Fig. 4), we can estimate an average shift of the hypocenters in the studied area. The locations become shallower by about $2.6 \mathrm{~km}$ and move to about $0.4 \mathrm{~km}$ north and $1.3 \mathrm{~km}$ west when we use the arrival times at the temporary stations. Therefore we moved all of the hypocenters determined in step 2 by the amount of the offsets (step 3 in Fig. 3), which are considered as absolute locations.

Earthquake locations are distributed at depths from 2 to 

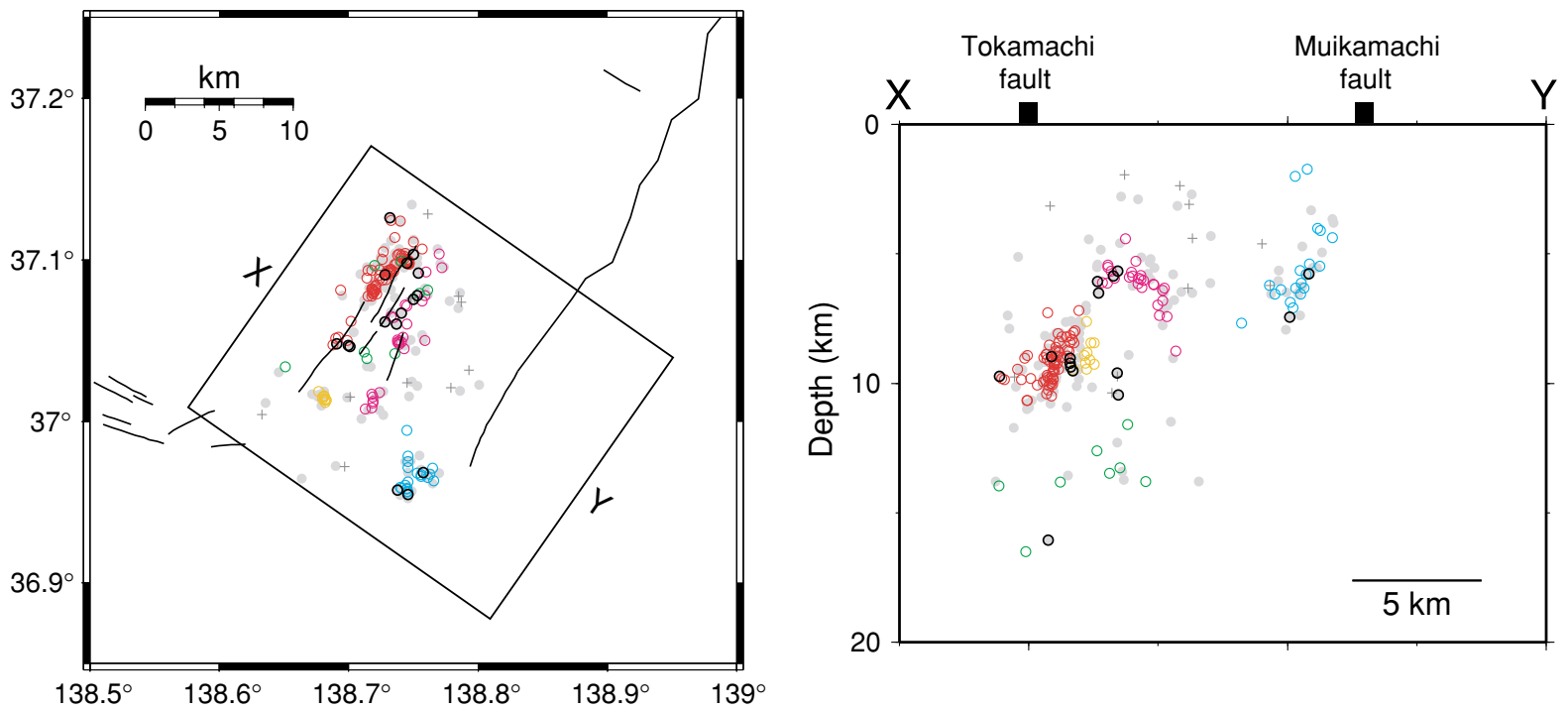

$$
\begin{array}{llll}
\circ \text { cluster A } & \circ \text { cluster } \mathrm{C} & \circ \text { cluster } \mathrm{E} & \circ \text { before DD relocation } \\
\text { cluster B } & \circ \text { cluster D } & + \text { other } & \circ \text { events used for the location shifts }
\end{array}
$$

Fig. 4. Hypocenters determined in this study before (gray dots) and after double-difference relocation (other symbols). Five clusters were detected. Locations are shown in map view (left) and cross-section (right).

$17 \mathrm{~km}$ (gray dots in Fig. 4), a depth range that is consistent with those of the aftershocks of the 2004 Mid-Niigata earthquake (Sakai et al., 2005). In contrast to the JMA catalogue, the hypocenters clustered and moved to the northwest at about 2-5 km. In particular, the locations show not only NW dipping planes but also SE dipping ones, which are not clearly identified in the JMA catalogue.

\subsection{Relative locations}

In order to reveal fine fault structures, we next applied the double-difference earthquake location algorithm of Waldhauser and Ellsworth (2000) to the $P$ - and $S$-wave arrival time data (step 4 in Fig. 3). Each event is linked to their neighbors through commonly observed phases, with the average distance between linked events being $5 \mathrm{~km}$. The relocated hypocenters present a sharp view of the seismicity and reveal five discrete clusters (Fig. 4). First, we find a cluster having a NW dipping plane at the bottom of the surface trace of the Tokamachi fault (cluster A). The dip angle is about $70^{\circ}$ or greater. The depth range of the cluster is about $7-11 \mathrm{~km}$. The activity of the cluster is highest in the present studied area. In this cluster, swarm-like activity occurred on March 28, 2002 and continued for about one month, in which the largest event was $\mathrm{M}_{\mathrm{JMA}} 4.1$ (Japan Meteorological Agency, 2002). Figure 5(a) is the magnitude-time plot of this cluster, showing that the activity level seems to be gradually decreasing before the mainshock of the 2004 MidNiigata earthquake, but increases afterwards. A second cluster is identified in the southern part of the Tokamachi fault at a depth range of 7-10 km (cluster B). The cluster is the swarm activity that occurred in July and August 2002 (Fig. 5(b)). A third cluster is located at the southern end of the Muikamachi fault, whose depth range is about 2-8 $\mathrm{km}$ (cluster C). In this cluster, a moderate-sized earthquake $\left(\mathrm{M}_{\mathrm{JMA}}\right.$ 5.1) occurred on January 4, 2001. This was a reverse faulting with a strike-slip component. Some of the activity
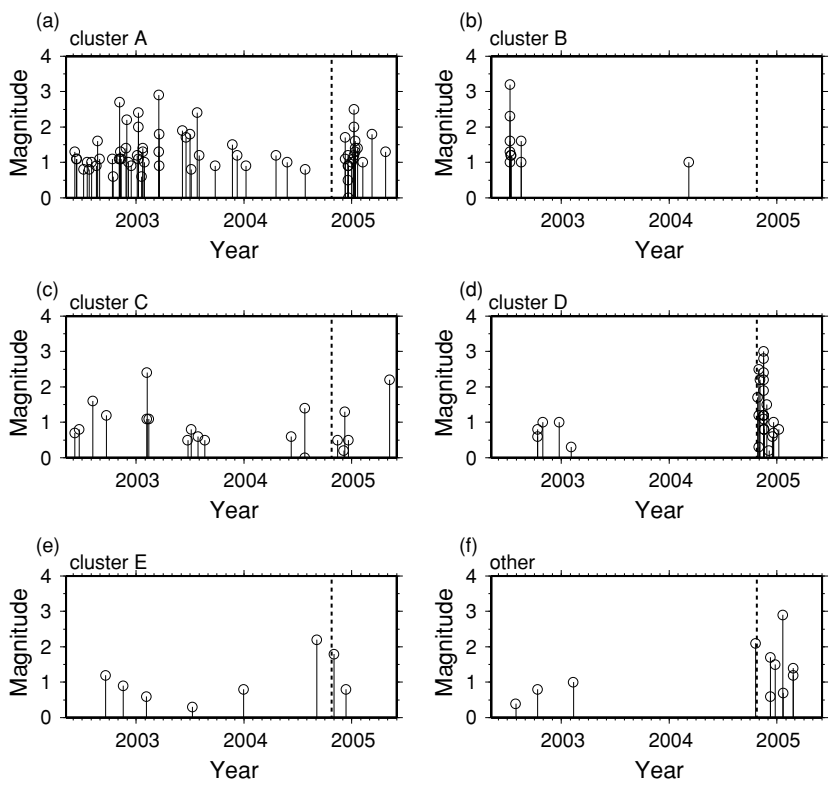

Fig. 5. The magnitude-time plots for earthquakes occurring in the five clusters defined in Fig. 4. Dotted lines correspond to the occurrence of the 2004 Mid-Niigata prefecture earthquake.

in the cluster $\mathrm{C}$ might be the aftershocks of the event. A fourth cluster has a SE dipping plane with an angle of about $40^{\circ}$ (cluster D). The depth range is $4-9 \mathrm{~km}$. It should be noted that the cluster clearly became active after the occurrence of the 2004 event (Fig. 5(d)). The last cluster (cluster E) exists at a depth of between 11 and $17 \mathrm{~km}$, which is clearly deeper than that of other clusters. The activity in the cluster $\mathrm{E}$ is relatively low, but continuously appears (Fig. 5(e)). The cluster seems to have a NW dipping plane with a dip angle of about $30^{\circ}$. 


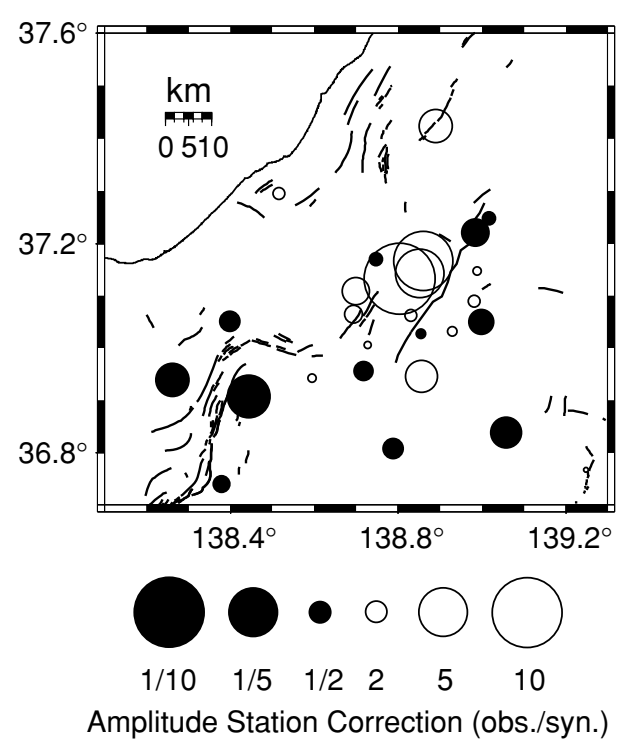

Fig. 6. $P$-wave amplitude station corrections on map view.

\section{Stress Field in the Seismic Gap \\ 5.1 Focal mechanism solutions}

Focal mechanisms are ordinarily determined from $P$ wave polarity data. In the case of small earthquakes, however, it is difficult to obtain a unique focal mechanism solution, because the number of stations detecting events decreases and their azimuthal coverage becomes poor. One approach to overcoming this problem is to use $S / P$ amplitude ratios (Kisslinger, 1980; Julian and Foulger, 1996; Hardebeck and Shearer, 2003) or absolute $P$ and $S$ amplitudes (Slunga, 1981; Nakamura et al., 1999; Igarashi et al., 2001).

In this study, we determined the focal mechanism solutions using absolute $P$ and $S H$ amplitudes and $P$-wave polarity. The approach was used in Imanishi et al. (2006) and shown to be effective for micro-earthquakes. After correcting the instrumental response, we determined the spectral levels and corner frequencies of the spectra by fitting the $\omega^{2}$-model (Boatwright, 1978) with an attenuation correction. The spectral levels for lower frequencies were used as observed amplitudes. Although the corner frequency and the attenuation correction are highly dependent on one another and are not well resolved from each other in the spectral fitting, the spectral levels can be stably estimated (e.g., Imanishi et al., 2004). Theoretical amplitudes were calculated from the far-field solutions for a shear point-source dislocation in a homogeneous infinite medium with corrections of the incident angles at the surface and geometrical spreading. The best-fit solution of each event was determined by minimizing the residual between the observed and theoretical amplitudes, where a grid search approach is conducted for strike, dip and slip angles with $5^{\circ}$ intervals. Since amplitudes are used, the seismic moment of each event can also be determined.

The actual procedures of this analysis are as follows: We first determined the tentative focal mechanism solutions and seismic moments of 26 events where the number of P-wave polarity data was 10 or greater. We then calculated the log-

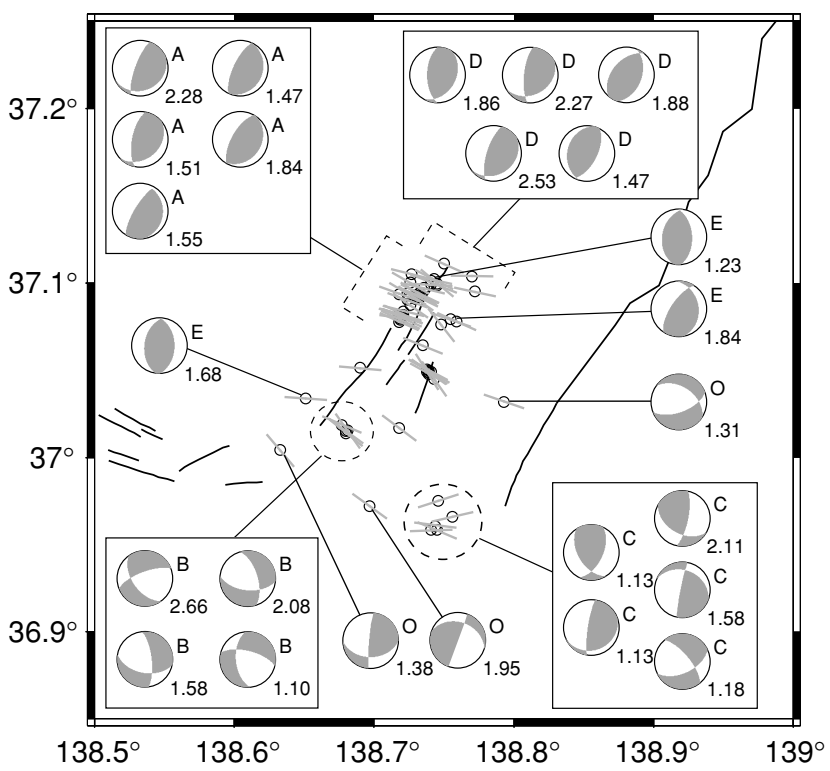

Fig. 7. Focal mechanism solutions determined in this study. The lower hemisphere of each solution is shown using equal-area projection. Compressive quadrants are shaded. Moment magnitude (Hanks and Kanamori, 1979) is shown at the right bottom corner. The alphabets at the right top corner denote the cluster name, where " $O$ " represents "other events". For clusters A and D, we show only five representative solutions. The directions of the $P$-axis are also shown by gray lines.

arithmic average of the ratios between the observed and theoretical amplitudes of the 26 events, which was used as the amplitude station correction at each station. Using the amplitude station corrections, we redetermined the focal mechanism solutions and seismic moments of the 26 events. In the same way, we obtained the focal mechanisms and seismic moments of events with at least five polarity data. The stability of the solution was checked by plotting all focal mechanisms whose residual was less than 1.1 times the minimum residual value. We omitted ambiguous solutions where several solutions were possible. In total, we obtained 55 focal mechanisms. The moment magnitude (Hanks and Kanamori, 1979) ranged from 1.0 to 2.7 .

Figure 6 plots the $P$-wave amplitude station corrections on the map view. A similar pattern is obtained for the $S$ wave amplitude station corrections. The amplitude station corrections generally depend on surface geology, where the large amplitude corrections were obtained in the sedimentary basin. Such a correlation between the site response and surface geology is often reported (e.g., Hartzell et al., 1996). Figure 7 shows the determined focal mechanism solutions. For the clusters $\mathrm{A}$ and $\mathrm{D}$, we show five representative solutions for the sake of simplicity. Most of the events are reverse faulting events whose strikes are similar to those of the Muikamachi and Tokamachi faults. For the clusters A, D and E, the dip angles of each cluster are well consistent with those of the focal mechanisms, suggesting clusters $\mathrm{A}$ and $\mathrm{E}$ are NW dipping reverse fault planes and that cluster D is a SE dipping reverse fault plane. Earthquakes occurring at the southern part of the present studied area (clusters B and C and two other events) contain some strike-slip components. 
(a) cluster A, D, E
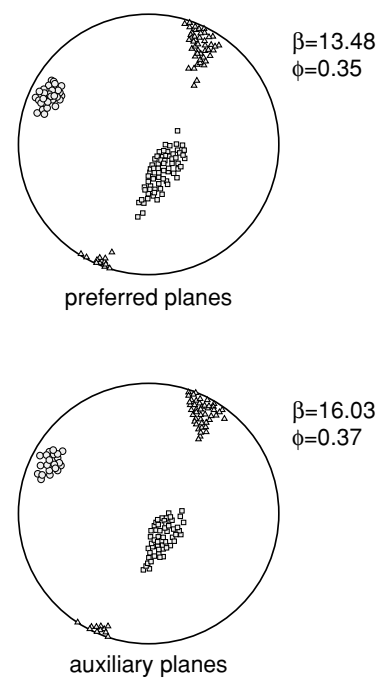

cluster B, C, and other two events

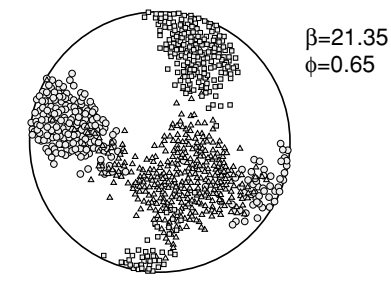

\begin{tabular}{c|c|}
$95 \%$ confidence region \\
$\circ \mathrm{S}_{1}$ \\
$\therefore \mathrm{S}_{2}$ \\
$\cdot \mathrm{S}_{3}$ \\
\hline
\end{tabular} (b)

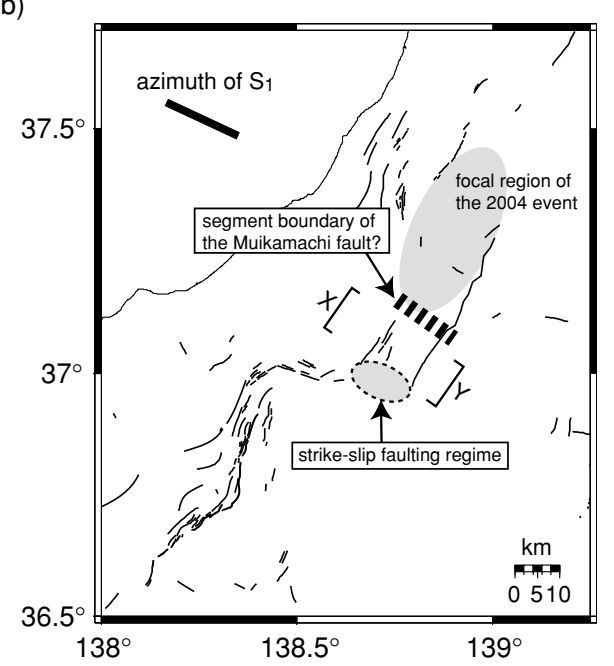

Fig. 8. (a) Stress inversion results for two subsets. Principal stress axes with their $95 \%$ confidence limits are plotted on lower hemisphere stereonets. Stress state changes at the southern ends of the Muikamachi and Tokamachi faults from the thrust faulting to the strike-slip faulting regime (b).

\subsection{Stress inversion}

Using the focal mechanism solutions determined above, we calculated the directions of the seismogenic stress tensor by applying the inversion method of Michael (1984). The inversion solves for the orientation of the three principal stress axes and the relative magnitude of the principal stresses defined by $\phi=\left(S_{2}-S_{3}\right) /\left(S_{1}-S_{3}\right)$, where $S_{1}, S_{2}$, and $S_{3}$ are the maximum, intermediate, and minimum compressive principal stresses, respectively. Since the stress inversion assumes that all of the earthquakes included in the inversion occur under a single-stress state, we divided the entire data set into two subsets based on earthquake locations and focal mechanism solutions. The first includes clusters A, D, and E, while the second is composed of clusters B and C and two other events containing some strikeslip component. The number of focal mechanisms for the first and second subsets is 43 and 12, respectively.

One plane must be chosen from each focal mechanism as the actual fault plane, since the inversion uses the direction of the tangential traction on the fault plane. For the first subset, it is rather easy to choose fault planes. Preferred planes were selected so that they would align with a plane imaged by the clusters (Fig. 4). However, since there is no guarantee that all the events occur on the assumed planes, the inversion was also run on the auxiliary planes, and we estimated how the choice of plane affected the solution. In contrast, it is difficult to select the preferred planes from the alignment of the clusters for the second subset due to the existence of various focal mechanism solutions. We chose the preferred fault planes while inverting for the stress tensor based on Michael's (1987) grid search algorithm, which is a rational approach in situations where the choice of the fault planes cannot be made on the basis of relative hypocentral locations or of geological information (Kastrup et al., 2004). There are four variables in the grid search algorithm: the trend and plunge of the $S_{3}$ axis, a rotation angle of the $S_{2}$ axis about the $S_{3}$ axis, and $\phi$. The grid search was performed using a $5^{\circ}$ grid for all of the angular variables and $\phi$ was searched in steps of 0.1 .

The 95\% confidence region was computed by the bootstrap resampling technique for both the subset (Michael, 1987). We use 2000 bootstrap resamplings, which is adequate to produce stable confidence regions up to the $95 \%$ level (Michael, 1987). In order to include the effects of mispicked fault planes on the confidence region, each nodal plane has the same probability of being chosen during the resampling.

The results of the stress inversion for two subsets are plotted in Fig. 8(a). In all cases, the average misfit angles $(\beta)$ between the predicted tangential traction on the fault planes and the observed slip direction on each plane are small, suggesting a valid fit to the single stress tensor (Michael, 1991). For the first subset, the values of $\phi$, the stress directions, and the sizes of the $95 \%$ confidence regions are almost the same between the inversions of the preferred and auxiliary planes. Therefore, the conclusions of the stress tensor inversion for the first subset do not depend on the choice of fault plane. As seen in Fig. 8(a), the stress state in the second subset has large $95 \%$ confidence limits because of the small number of mechanisms available. In spite of this large $95 \%$ confidence interval, the stress state in the first subset is statistically different from that in the second one. The stress states in the first and second subset are characterized by a thrust faulting and strike-slip faulting regime, respectively. The determined azimuths of $S_{1}$ are WNW-ESE for both subsets that conform to the general tectonic trend in this area (e.g., Tsukahara and Kobayashi, 1991). For the first subset, in the case of the preferred planes, the azimuth and plunge of $S_{1}$ are estimated to be $\mathrm{N} 65^{\circ} \pm 9^{\circ} \mathrm{W}$ and $16^{\circ} \pm 9^{\circ}$, respectively. Here the error bars represent the $95 \%$ confidence limits. The azimuth of $S_{1}$ is almost perpendicular to the strikes of the Muikamachi and Tokamachi faults (Fig. 8(b)).

\subsection{Stress transferred to the southern end of the source region}

In order to evaluate the stress changes in the seismic gap, we computed Coulomb failure stress $(\triangle \mathrm{CFS})$ due to 
Table 2. Input parameters in the calculation of Coulomb failure stress.

\begin{tabular}{lcccccccc}
\hline & $\begin{array}{c}\text { Strike } \\
(\text { degree })\end{array}$ & $\begin{array}{c}\text { Dip } \\
(\text { degree })\end{array}$ & $\begin{array}{c}\text { Rake } \\
(\text { degree })\end{array}$ & $\begin{array}{c}\text { Average slip } \\
(\mathrm{m})\end{array}$ & $\begin{array}{c}\text { Length } \\
(\mathrm{km})\end{array}$ & $\begin{array}{c}\text { Width } \\
(\mathrm{km})\end{array}$ & $\begin{array}{c}\text { Depth of the } \\
\text { fault’s top }(\mathrm{km})\end{array}$ & $\begin{array}{c}\text { Released } \\
\text { moment }(\mathrm{Nm})\end{array}$ \\
\hline Mainshock & 215 & 60 & 90 & 1.20 & 25 & 10 & 5 \\
Largest aftershock & 215 & 60 & 90 & 0.89 & 15 & 10 & 7 & $4.0 \times 10^{18}$ \\
\hline
\end{tabular}

(b) cluster $\mathrm{A}$

(a)

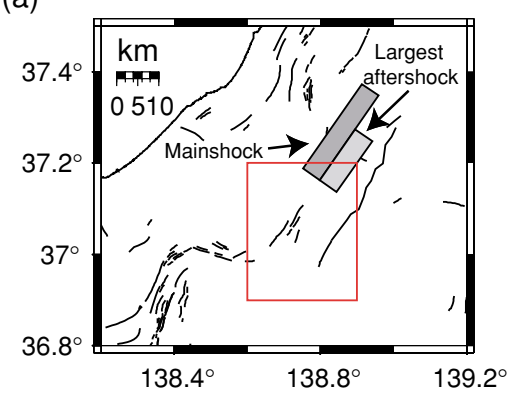

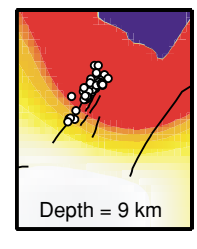

(c)

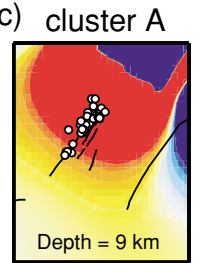

cluster D

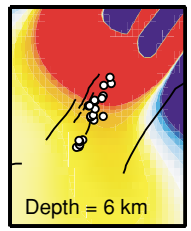

cluster D

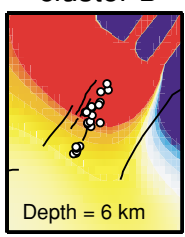

cluster E

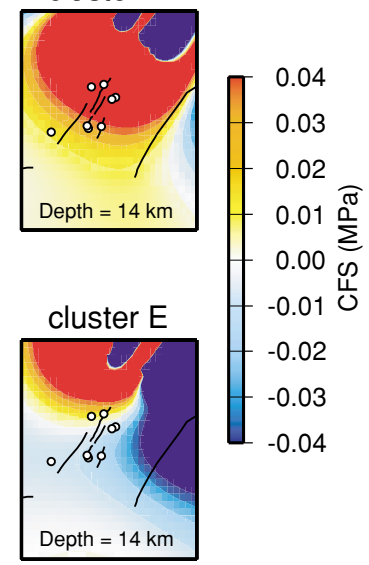

Fig. 9. Coulomb failure stresses caused by the mainshock (M $\mathrm{M}_{\mathrm{JA}}$ 6.8) and the largest aftershock (MJMA 6.5) of the 2004 Mid-Niigata earthquake. (a) The surface projections of the mainshock and the largest aftershock are shown by large and small shaded rectangles, respectively. (b) and (c) Map views of Coulomb failure stresses resolved onto the plane of clusters A, D and E. The values within the red rectangle in (a) are shown. White circles are the earthquake locations of each cluster.

the mainshock and the largest aftershock of the 2004 MidNiigata earthquake. Calculations were made in an elastic half-space following Okada (1992) by assuming a shear modulus of $30 \mathrm{GPa}$ and a Poisson ratio of 0.25 . The input parameters in the $\triangle \mathrm{CFS}$ calculation were determined by finite-fault models (Yamanaka, 2004) and aftershock distributions (Sakai et al., 2005), which are listed in Table 2 and drawn in Fig. 9(a). The apparent friction coefficient, which includes the influences of both mechanical friction and pore fluid pressure, was assumed to be 0.4 .

We calculated $\triangle \mathrm{CFS}$ resolved onto the planes inferred from the alignments of the clusters A (strike $215^{\circ}$, dip $70^{\circ}$, rake $90^{\circ}$ ), $\mathrm{D}$ (strike $35^{\circ}$, dip $40^{\circ}$, rake $90^{\circ}$ ), and $\mathrm{E}$ (strike $215^{\circ}$, dip $30^{\circ}$, rake $90^{\circ}$ ) at the depth where each cluster mainly occurred (Fig. 9(b)). As mentioned previously, it is difficult to demonstrate that all the events in each cluster occur on the plane parallel to the dipping angles of the cluster. Therefore, we also calculated $\triangle \mathrm{CFS}$ resolved onto the planes perpendicular to the alignments of the clusters, where the receiver faults are as follows: A (strike $35^{\circ}$, dip $20^{\circ}$, rake $90^{\circ}$ ), D (strike $215^{\circ}$, dip $50^{\circ}$, rake $90^{\circ}$ ), and $\mathrm{E}$ (strike $35^{\circ}$, dip $60^{\circ}$, rake $90^{\circ}$ ) (Fig. 9(c)). Regardless of the assumed receiver faults, the clusters $\mathrm{A}$ and $\mathrm{D}$ occurred in positive $\triangle \mathrm{CFS}$ regions with a value of about $0.01 \mathrm{MPa}$ or greater, which is likely to be large enough to trigger a seismicity (Reasenberg and Simpson, 1992). This is consistent with the observational evidence that these clusters became active following the 2004 event (Figs. 5(a) and (d)). For cluster $\mathrm{E}$, the $\triangle \mathrm{CFS}$ depends on the assumed receiver faults. For the receiver fault perpendicular to the alignments of cluster $\mathrm{E}$, the $\triangle \mathrm{CFS}$ becomes negative, which is consis- tent with the observational evidence that prominent activity after the mainshock has not been observed in cluster E (Fig. $5(\mathrm{e})$ ). In contrast, the $\triangle \mathrm{CFS}$ at cluster $\mathrm{E}$ becomes positive with a value of about $0.01 \mathrm{MPa}$ or greater for the receiver fault inferred from the alignment of the cluster. If so, for a better understanding of the seismic risk in the region, it is important to investigate why the activities of cluster $E$ were not triggered, although the increments of the $\triangle \mathrm{CFS}$ in cluster $\mathrm{E}$ are almost same as those in clusters A and D. Since the present data alone cannot reveal it, further study is required in the future.

Unlike in clusters A, D and E, it is difficult to assume a receiver fault for clusters $B$ and $C$ due to the existence of various focal mechanism solutions (Fig. 7). In order to evaluate the stress changes for clusters B and C, we calculated $\triangle \mathrm{CFS}$ on the nodal planes of nine focal mechanism solutions that were determined in this study (Fig. 7). We consider that these focal mechanism solutions are typical for earthquakes that can be generated at clusters B and C. We found that four out of 18 nodal planes had $\triangle \mathrm{CFS}>0.01$ $\mathrm{MPa}$, and that the maximum value was only 0.015 $\mathrm{MPa}$. This result agrees with the observational evidence that clusters $\mathrm{B}$ and $\mathrm{C}$ were not activated after the occurrence of the 2004 event (Figs. 5(b) and (c)).

\section{Discussion}

It is important to explore the fault geometries of active faults at depths to understand the generation process of inland earthquakes and to predict the strong ground motion associated with a scenario earthquake. The northern part of the Muikamachi fault is contained in the source region 
of the 2004 Mid-Niigata earthquake (Fig. 1). According to the precise aftershock locations (Sakai et al., 2005), the mainshock has a NW dipping plane in a depth range of 3$14 \mathrm{~km}$. The fault plane reduces its dip angle at depths of less than $5 \mathrm{~km}$, and its extension to the surface seems to intersect at the surface trace of the Muikamachi fault. Such fault geometry in the depths is supported by a balanced section constructed from geological structures (Okamura and Yanagisawa, 2005; Sato and Kato, 2005).

Here we discuss the relationship between the deep and shallow fault structures of the southern part of the Muikamachi and Tokamachi faults based on precise earthquake locations and the surface trace of those active faults. Since it is difficult to estimate the unique solution of their geometries from our own data, we can only show a few possibilities. Focal mechanisms and earthquake locations suggest that clusters A, D, and E are candidates for deep structures of the southern part of the Muikamachi fault. If cluster A is relevant to the deep structure of the Muikamachi fault, the geometry of the fault should decrease its dip angle at shallow depths as shown by a dotted curve in Fig. 10, a geometry that is similar to the geometry of the mainshock fault plane. As expected from the alignment of cluster E, the fault geometry, as shown by a solid curve in Fig. 10 is also a candidate of the deep structure of the southern part of the Muikamachi fault. In this case, the fault dip should gradually decrease with increasing depth. There exists another possible fault geometry, as shown by the bold gray line in Fig. 10, which intersects with both clusters A and D. In this case, the macroscopic fault plane is not parallel to the alignments of clusters A and D. However, since the width of these clusters is short (no more than $4 \mathrm{~km}$ ), those alignments are not always parallel to the macroscopic fault plane. In contrast with the source region, the present studied area has simple anticline structures (Yanagisawa et al., 1985). A balanced section constructed from the geological structures suggests that the fault geometry should be simple (Okamura and Yanagisawa, 2005; Sato and Kato, 2005). Therefore, the first possibility seems to be discounted, and we prefer the latter two cases as the deep fault geometry of the southern part of the Muikamachi fault. It should be noted that our preferred fault geometries of the southern part of the Muikamachi fault differ from that of the mainshock. According to $\operatorname{Kim}(2001,2004)$, the vertical slip rate of the fault is different between the northern area (0.8-1.0 $\mathrm{mm} / \mathrm{yr})$ and the southern area $(2.0 \mathrm{~mm} / \mathrm{yr})$. It is likely that the Muikamachi fault is divided into two segments whose boundary corresponds to the southern end of the source region of the 2004 Mid-Niigata earthquake (Fig. 8(b)), and that the ruptured area by the mainshock was terminated due to the fault segment boundary.

The extension of the alignment of cluster D intersects at the surface trace of the Tokamachi fault (Fig. 4(b)), suggesting the possibility that the deep structure of the eastern Tokamachi fault corresponds to cluster D. If this is the case, the eastern Tokamachi fault has a SE dipping plane with an angle of about $40^{\circ}$ in the depths as shown by a gray dotted curve in Fig. 10. However, the short width of the cluster makes it difficult to definitively demonstrate the geometry. Since the western as well as the eastern Tokamachi

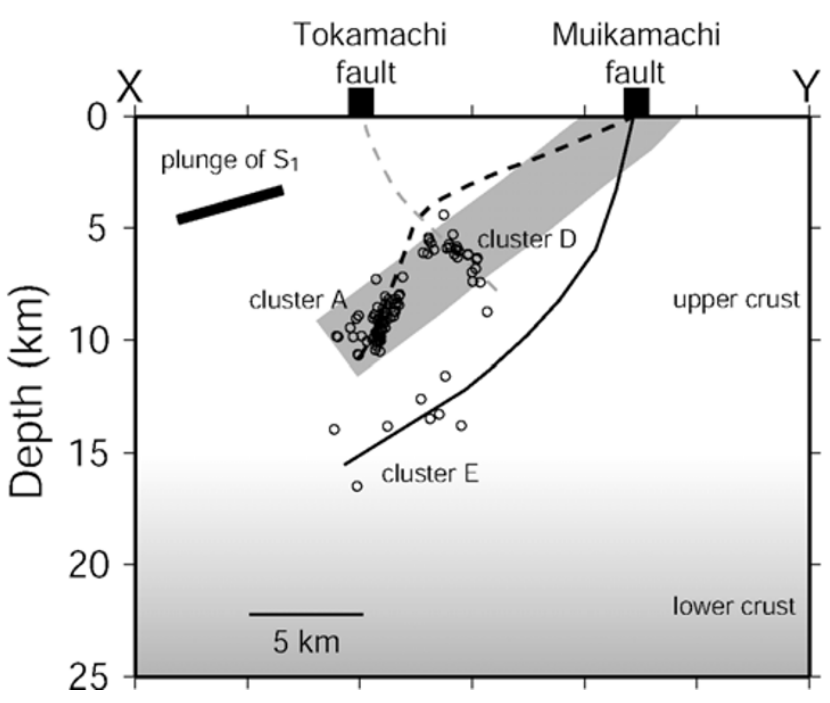

Fig. 10. An interpretation of fault structures in the seismic gap along $\mathrm{X}-\mathrm{Y}$ shown in Fig. 8(b).

faults have the potential to cause significant damage in the surrounding area, further work is needed to elucidate their deep fault structures.

The angle between the fault plane and the maximum principal stress is important in the investigation of the stress state along the fault. For the two preferred fault geometries of the southern part of the Muikamachi fault, the angles between the $S_{1}$ and the fault planes are about $15^{\circ}$ (Fig. 10). The angle implies that the shear stress resolving along the preferred fault planes is large. In addition, the Coulomb failure stresses induced by the mainshock and the largest aftershock of the 2004 Mid-Niigata earthquake are positive on the preferred fault plane deduced from the alignment of cluster E (Fig. 9(b)). As expected, the Coulomb failure stresses also become positive on another preferred fault plane. This evidence suggests that the seismic risk in the seismic gap is high.

There are active faults trending in the WNW-ESE direction between the Tokamachi fault and the western marginal fault zone of Nagano basin (Fig. 1). Most of these faults are reverse faults dipping to the south (Research Group for Active Faults in Japan, 1991). The region is also considered to be the seismic gap between the 2004 Mid-Niigata earthquake and the 1847 Zenkoji earthquake, so that the seismic risk in the region should be investigated. As seen in Fig. 8(b), the azimuth of $S_{1}$ estimated in the studied area is almost parallel to the trend of these active faults. If the azimuth of $S_{1}$ does not significantly vary, it is supposed that these faults could not easily slip in the present stress state. However, since the stress field can be spatially heterogeneous with a length scale of tens of kilometers or less (Hardebeck and Hauksson, 2001), it is not appropriate to apply the estimated stress field even in the adjacent regions. We established a dense temporary seismic observation with a spacing of 5-10 km on July 2005 in the above region as well as around the western marginal fault zone of the Nagano basin. By analyzing the new data collected by the seismic observation, we may gain a much better understanding of the seismic risk in the seismic gap. 


\section{Conclusion}

The seismicity, fault structures, and stress field in the seismic gap adjacent to the source region of the 2004 MidNiigata earthquake have been investigated based on precise earthquake locations and focal mechanism solutions. We detected five discrete clusters including a conjugate plane. Such a complex fault structure has also been found in the source region of the 2004 Mid-Niigata earthquake (Sakai et al., 2005), suggesting that this is a common feature in this region. Focal mechanism solutions suggest that most of the events are reverse faulting events whose strikes are similar to those of the Muikamachi and Tokamachi faults, while earthquakes occurring at the southern part of the present studied area contain some strike-slip components. A stress tensor inversion shows that the stress state slightly changes at the southern end of the Muikamachi and Tokamachi faults from the thrust faulting to the strike-slip faulting regime.

We have shown two possibilities for the deep fault geometry of the southern part of the Muikamachi faults. Comparing with the fault geometry of the mainshock, the Muikamachi fault might be divided into two segments whose boundary corresponds to the southern end of the source region. It is likely that the area ruptured by the mainshock was terminated due to the fault segment boundary. The angle between the maximum principal stress and the preferred fault planes implies that the shear stress resolving along the planes are large. Furthermore, the Coulomb failure stresses induced by the mainshock and the largest aftershock increase along the preferred fault planes of the southern part of the Muikamachi faults. This evidence suggest a high seismic risk in the seismic gap.

Acknowledgments. The seismograph stations used in this study include permanent stations operated by NIED, JMA and ERI. We are grateful to JMA for the hypocenter list. Comments by two anonymous reviewers were helpful in improving the manuscript. We thank F. Waldhauser, W. L. Ellsworth, A. Michael, and Y. Okada for the use of their codes in the relocation analysis and stress field investigations. K. Uehira modified the HYPOMH program (Hirata and Matsu'ura, 1987) for determining earthquake locations based on two different velocity structures. We modified a program by S. Ide for estimating focal mechanisms. A. Kato and S. Sakai provided preprints of their work. All figures have been generated using the Generic Mapping Tool (Wessel and Smith, 1998). K. I. was supported by a Grant-in-Aid for Scientific Research of the Ministry of Education, Sports, Science and Technology of Japan.

\section{References}

Aoki, S., M. Nishi, K. Nakamura, T. Hashimoto, S. Yoshikawa, and H. Ito, Multi-planar structures in the aftershock distribution of the Mid-Niigata prefecture Earthquake in 2004, Earth Planets Space, 57, 411-416, 2005. Boatwright, J., Detailed spectral analysis of two small New York State earthquakes, Bull. Seism. Soc. Am., 68, 1117-1131, 1978.

Geological Survey of Japan, AIST, Gravity CD-ROM of Japan, Ver. 2., Digital Geoscience Map P-2, 2004.

Hanks, T. C. and H. Kanamori, A moment magnitude scale, J. Geophys. Res., 84, 2348-2350, 1979.

Hardebeck, J. L. and E. Hauksson, Crustal stress field in southern California and its implications for fault mechanics, J. Geophys. Res., 106 , 21,859-21,882, 2001.

Hardebeck, J. L. and P. M. Shearer, Using S/P amplitude ratios to constrain the focal mechanisms of small earthquakes, Bull. Seism. Soc. Am., 93, 2434-2444, 2003

Hartzell, S., A. Leeds, A. Frankel, and J. Michael, Site response for ur- ban Los Angeles using aftershocks of the Northridge earthquake, Bull. Seism. Soc. Am., 86, S168-S192, 1996.

Hashimoto, M., Horizontal strain rates in the Japanese Islands during interseismic period deduced from geodetic surveys (Part I): Honshu, Shikoku and Kyushu, Zisin, 43, 13-26, 1990 (in Japanese with English abstract).

Hirata, N. and M. Matsu'ura, Maximum-likelihood estimation of hypocenter with origin time eliminated using nonlinear inversion technique, Phys. Earth Planet. Inter., 47, 50-61, 1987.

Igarashi, T., T. Matsuzawa, N. Umino, and A. Haspegawa, Spatial distribution of focal mechanisms for interpolate and intraplate earthquakes associated with the subducting pacific plate beneath the northeastern Japan arc: A triple-planed deep seismic zone, J. Geophys. Res., 106, 2177-2191, 2001

Ikeda, Y., T. Imaizumi, M. Togo, K. Hirakawa, T. Miyauchi, and H. Sato, Atlas of Quaternary Thrust Faults in Japan, University of Tokyo Press, 254 pp., 2002.

Imanishi, K., W. L. Ellsworth, and S. Prejean, Earthquake source parameters determined by the SAFOD Pilot Hole seismic array, Geophys. Res. Lett., 31, L12S09, doi:10.1029/2004GL019420, 2004.

Imanishi, K., Y. Kuwahara, and Y. Haryu, Off-fault aftershocks of the 2005 West Off Fukuoka Prefecture Earthquake: Reactivation of a structural boundary?, Earth Planets Space, 58, 81-86, 2006.

Japan Meteorological Agency, Seismic activity in the Kanto and Chubu Districts, and adjacent areas (November 2001-May 2002), Report of the coordinate committee for earthquake prediction, 68, 72-82, 2002.

Julian, B. R. and G. R. Foulger, Earthquake mechanisms from linearprogramming inversion of seismic-wave amplitude ratios, Bull. Seismol. Soc. Am., 86, 972-980, 1996.

Kastrup, U., M. L. Zoback, N. Deichmann, K. F. Evans, D. Giardini, and A. J. Michael, Stress field variations in the Swiss Alps and the northern Alpine foreland derived from inversion of fault plane solutions, J. Geophys. Res., 109, doi:10.1029/2003JB002550, 2004.

Kato, A., E. Kurashimo, N. Hirata, S. Sakai, T. Iwasaki, and T. Kanazawa, Imaging the source region of the 2004 mid-Niigata prefecture earthquake and the evolution of a seismogenic thrust-related fold, Geophys. Res. Lett., 32, L07307, doi:10.1029/2005GL022366, 2005.

Kim, H. Y., Active faults along the western margin of the Muikamachi basin, central Japan, The Quaternary Research, 40, 161-168, 2001.

Kim, H. Y., Relationship between the upheaval process of the Uonuma Hills and the cumulative nature of the Muikamachi fault, central Japan, Active Fault Research, 24, 63-75, 2004 (in Japanese with English abstract).

Kisslinger, C., Evaluation of $\mathrm{S}$ to $\mathrm{P}$ amplitude ratios for determining focal mechanisms from regional network observations, Bull. Seismol. Soc. Am., 70, 999-1014, 1980.

Korenaga, M., S. Matsumoto, Y. Iio, T. Matsushima, K. Uehira, and T. Shibutani, Three dimensional velocity structure around aftershock area of the 2004 mid-Niigata prefecture earthquake (M6.8) by the DoubleDifference tomography, Earth Planets Space, 57, 429-433, 2005.

Lin, J. and R. S. Stein, Stress triggering in thrust and subduction earthquakes and stress interaction between the southern San Andreas and nearby thrust and strike-slip faults, J. Geophys. Res., 109, B02303, doi:10.1029/2003JB002607, 2004

Michael, A. J., Determination of stress from slip data: faults and folds, $J$. Geophys. Res., 89, 11,517-11,526, 1984.

Michael, A. J., Use of focal mechanisms to determine stress: A contro study, J. Geophys. Res., 92, 357-368, 1987.

Michael, A. J., Spatial variations in stress within the 1987 Whittier Narrows, California, aftershock sequence: New techniques and results, $J$. Geophys. Res., 96, 6303-6319, 1991.

Nakamura, A., S. Horiuchi, and A. Hasegawa, Joint focal mechanism determination with source-region station corrections using short-period body-wave amplitude data, Bull. Seismol. Soc. Am., 89, 373-383, 1999.

Neotectonics Research Group of the Niigata Shinano River Region, Chronology and development process of late Quaternary fluvial terraces in the Tsunan area of the Shinano river, central Japan, The Quaternary Research, 41, 199-212, 2002.

Okada, T., N. Umino, T. Matsuzawa, J. Nakajima, N. Uchida, T. Nakayama, S. Hirahara, T. Sato, S. Hori, T. Kono, Y. Yabe, K. Ariyoshi, S. Gamage, J. Shimizu, J. Suganomata, S. Kita, S. Yui, M. Arao, S. Hondo, T. Mizukami, H. Tsushima, T. Yaginuma, A. Hasegawa, Y. Asano, H. Zhang, and C. Thurber, Aftershock distribution and 3D seismic velocity structure in and around the focal area of the 2004 midNiigata prefecture earthquake obtained by applying double-difference tomography to dense temporary seismic network data, Earth Planets 
Space, 57, 435-440, 2005.

Okada, Y., Internal deformation due to shear and tensile faults in a halfspace, Bull. Seismol. Soc. Am., 82, 1018-1040, 1992.

Okada, Y., K. Kasahara, S. Hori, K. Obara, S. Sekiguchi, H. Fujiwara, and A. Yamamoto, Recent progress of seismic observation networks in Japan-Hi-net, F-net, K-NET and KiK-net, Earth Planets Space, 56, XV-Xxviii, 2004.

Okamura, Y. and Y. Yanagisawa, Relationship between the geologic structure and the Chuetsu earthquake, Chishitsu News, 607, 13-17, 2005.

Prejean, S. G., W. L. Ellsworth, M. Zoback, and F. Waldhauser, Fault structure and kinematics of the Long Valley Caldera region, California, revealed by high-accuracy earthquake hypocenters and focal mechanism stress inversions, J. Geophys. Res., 107(B12), doi:10.1029/ 2001JB001168, 2002.

Reasenberg, P. A. and R. W. Simpson, Response of regional seismicity to the static stress change produced by the Loma Prieta earthquake, Science, 255, 1687-1690, 1992.

Research Group for Active Faults of Japan, Active Faults of Japan, University of Tokyo Press, 1991 (in Japanese).

Sagiya, T., S. Miyazaki, and T. Tada, Continuous GPS array and presentday crustal deformation of Japan, Pure Appl. Geophys., 157, 23032322, 2000.

Sakai, S., N. Hirata, A. Kato, E. Kurashimo, T. Iwasaki, and T. Kanazawa, Multi-fault system of the 2004 Mid-Niigata Prefecture Earthquake and its aftershocks, Earth Planets Space, 57, 417-422, 2005.

Sato, H., The relationship between late Cenozoic tectonic events and stress field and basin development in northeastern Japan, J. Geophys. Res., 99, 22,261-22,274, 1994.

Sato, H. and N. Kato, Relationship between geologic structure and the source fault of the 2004 Mid-Niigata Prefecture Earthquake, central Japan, Earth Planets Space, 57, 453-457, 2005.

Shibutani, T., Y. Iio, S. Matsumoto, H. Katao, T. Matsushima, S. Ohmi, F. Takeuchi, K. Uehira, K. Nishigami, B. Enescu, I. Hirose, Y. Kano, Y. Kohno, M. Korenaga, Y. Mamada, M. Miyazawa, K. Tatsumi, T. Ueno, H. Wada, and Y. Yukutake, Aftershock distribution of the 2004 Mid Niigata Prefecture Earthquake derived from a combined analysis of temporary online observations and permanent observations, Earth Planets Space, 57, 545-549, 2005.

Slunga, R., Earthquake source mechanism determination by use of bodywave amplitudes- An application to Swedish earthquakes, Bull. Seismol. Soc. Am., 71, 25-35, 1981.

Stein, S. R. and G. Ekström, Seismicity and geometry of a 110-km-long blind thrust fault 2. Synthesis of the 1982-1985 California earthquake sequence, J. Geophys. Res., 97, 4865-4883, 1992.

Stein, S. R., A. A. Barka, and J. H. Dietrich, Progressive failure on the North Anatolian fault since 1939 by earthquake stress triggering, Geophys. J. Int., 128, 594-604, 1997.

Takeda, T., H. Sato, T. Iwasaki, N. Matsuda, S. Sakai, T. Iidaka, and A. Kato, Crustal structure in the northern Fossa Magna region, central Japan, modeled from refraction/wide-angle reflection data, Earth Planets Space, 56, 1293-1299, 2004.

Takeda, T., Y. Kuwahara, K. Imanishi, and Y. Haryu, Crustal structure in southern area of the 2004 Mid-Niigata earthquake by double-difference tomography method, Abstracts of Japan earth and planetary science joint meeting, S101-007, 2005.

Tanaka, M., A study of active faults related to folding, estimated from the deformation of fluvial terraces in the Tokamachi basin, central, Japan, The Quaternary Research, 39, 411-426, 2000.

Tsukahara, H. and Y. Kobayashi, Crustal stress in the central and western parts of Honshu, Japan, Zisin, 44, 221-231, 1991 (in Japanese with English abstract).

Urabe, T. and S. Tsukada, A workstation-assisted processing system for waveform data from microearthquake networks, Abstracts of Spring Meeting of Seismological Society of Japan, 70, 1991 (in Japanese).

Utsu, T., Seismicity studies: A comprehensive review, University of Tokyo Press, 1999 (in Japanese).

Waldhauser, F. and W. L. Ellsworth, A double-difference earthquake location algorithm: Method and application to the Northern Hayward fault, California, Bull. Seism. Soc. Am., 90, 1353-1368, 2000.

Wessel, P. and W. H. F. Smith, New, improved version of the Generic Mapping Tools released, EOS Trans. AGU, 79, 579, 1998.

Yamanaka, Y., EIC seismological notes, No. 154+ http://www.eri.u-tokyo. ac.jp/sanchu/Seismo_Note/2004/EIC154a.html, 2004.

Yanagisawa, Y., K. Chihara, I. Suzuki, T. Uemura, K. Kodama, and H. Kato, Geology of the Tokamachi district, with geological sheet map at 1:50,000, 104 pp., Geol. Surv. of Jpn., Tokyo, 1985 (in Japanese with English abstract).

Yanagisawa, Y., I. Kobayashi, K. Takeuchi, M. Tateishi, K. Chihara, and H. Kato, Geology of the Ojiya district, with geological sheet map at 1:50,000, 177 pp., Geol. Surv. of Jpn., Tokyo, 1986 (in Japanese with English abstract).

K. Imanishi (e-mail: imani@ni.aist.go.jp), Y. Kuwahara, T. Takeda, and Y. Haryu 